\title{
The Human Factors of an Early Space Accident: Flight 3-65 of the X-15
}

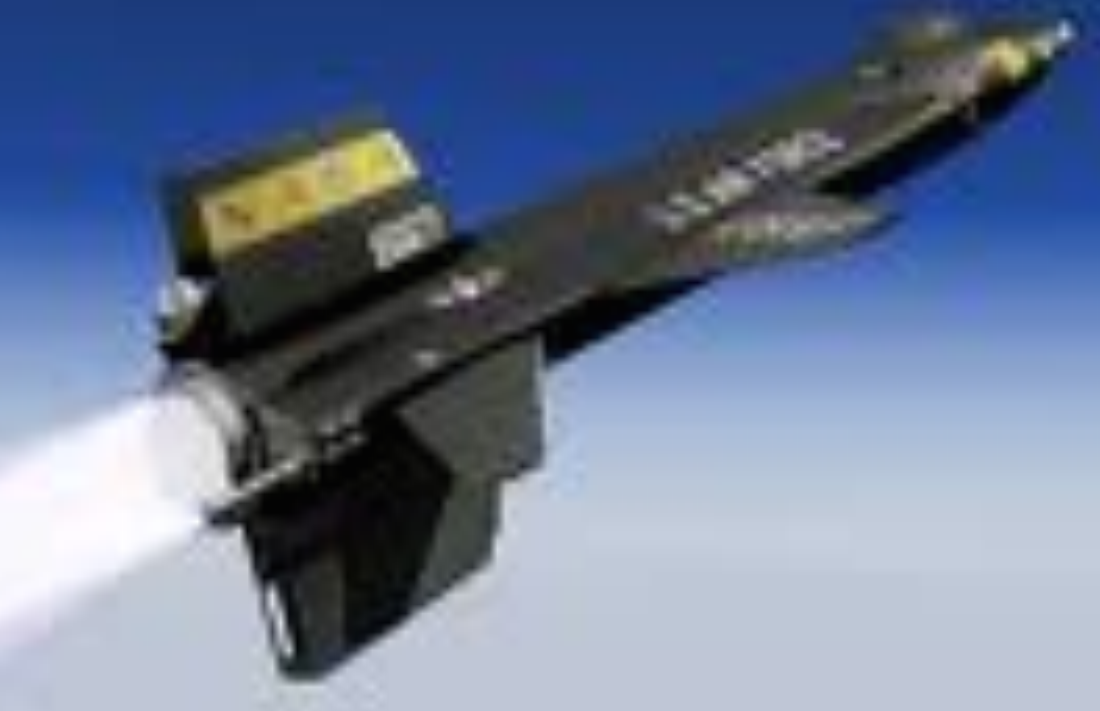

Immanuel Barshi, NASA Ames Research Center Irving C. Statler, NASA, Ames Associate (retired) With Jeb S. Orr, The Charles Stark Draper Laboratory, Inc. 


\section{USAF Major Michael J. Adams}

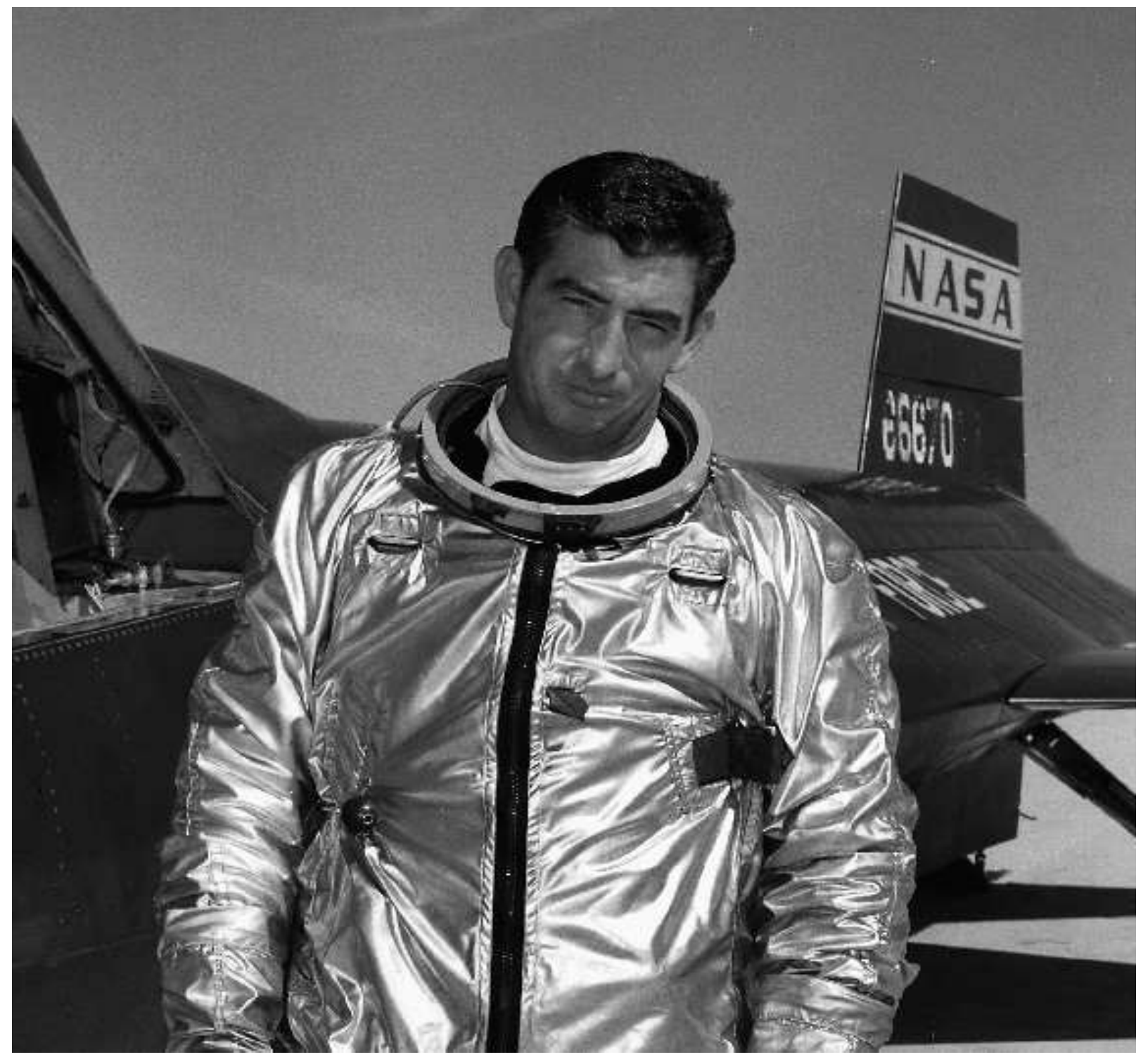


NASA FLIGHT RESEARCH CENTER

INVESTIGATION OF THE CRASH OF THE

X-15-3 AIRCRAFT ON NOVEMBER 15, 1967 


\section{The Highly Successful X-15 Research Program}

- $\mathrm{X}-15$ Program (1959 - 1968)

- Experimental rocket-powered research vehicle

- Research of all aspects of piloted hypersonic flight (especially altitude \& speed)

Achieved:

* 199 flights

* 4,519 mph (Mach 6.7)

* 354,200 ft (>67 mi)

Some flights qualified as space flights

* 13 flights exceeded AF criterion

* 2 flights exceeded FAl criterion

Data contributed to Projects Mercury, Gemini, \& Apollo as well as Space Shuttle 


\section{The X-15 Hypersonic Research Aircraft}

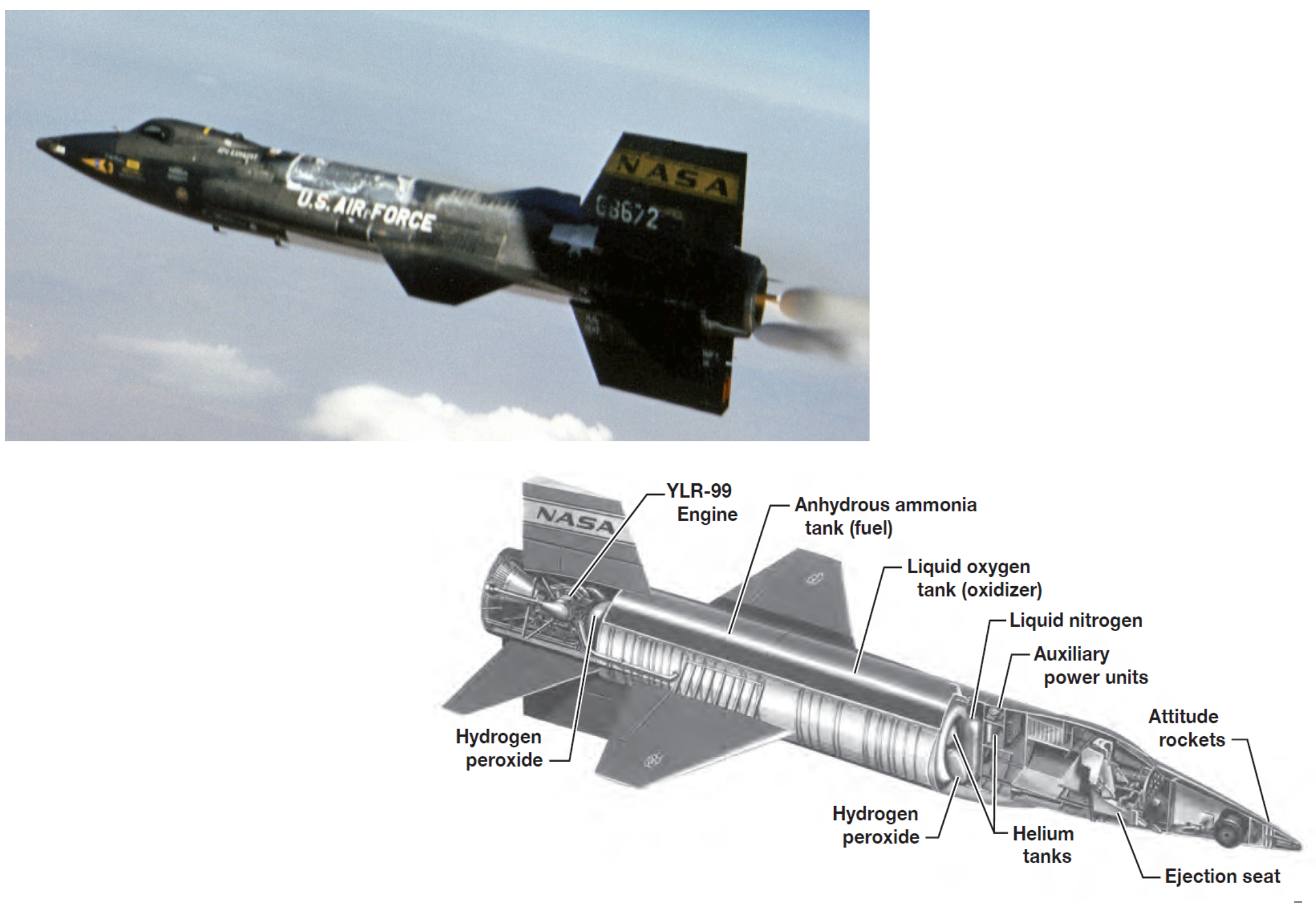




\section{Launch of the X-15 from the B-52}

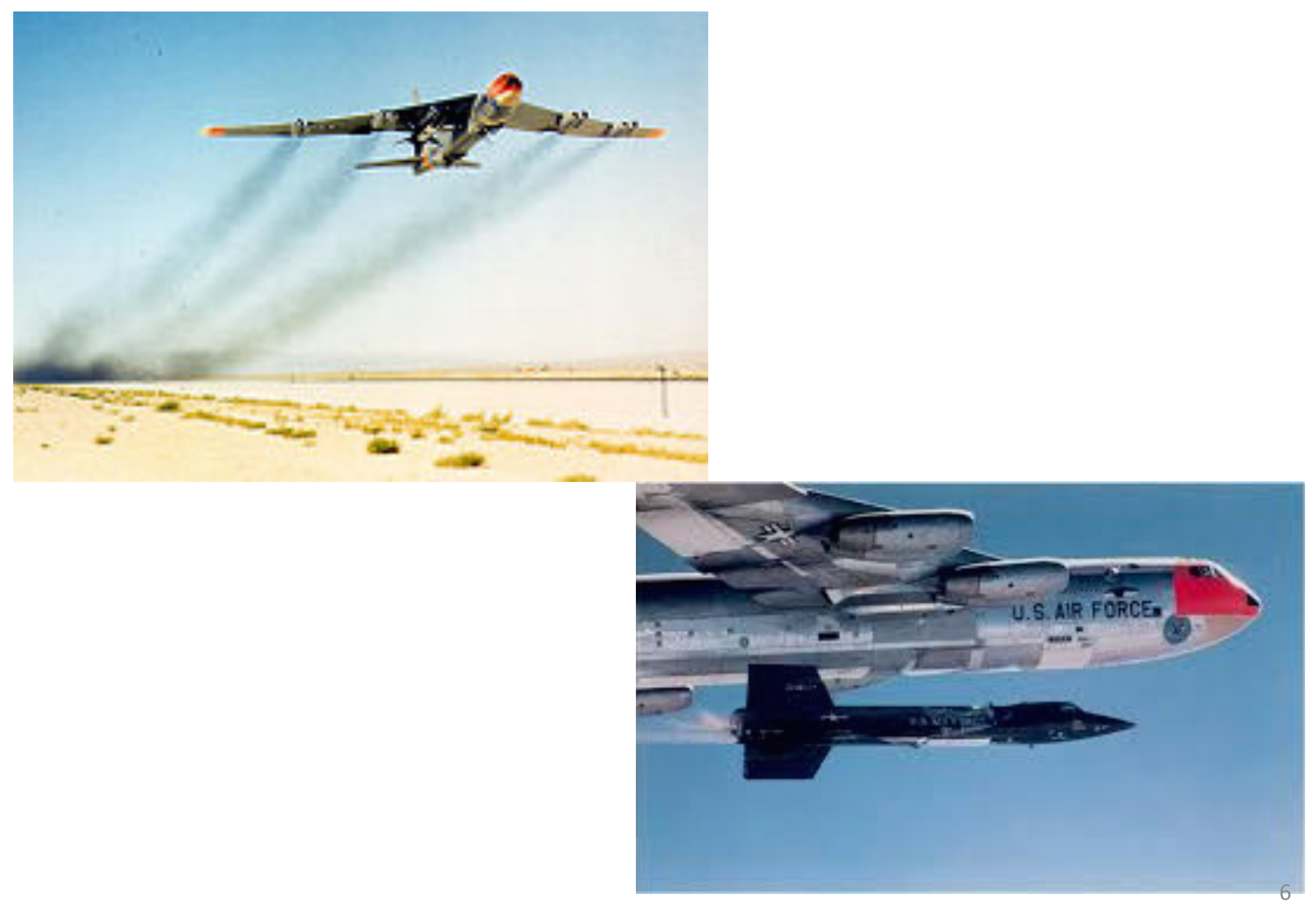




\section{TYPICAL X-15 RESEARCH MISSION}

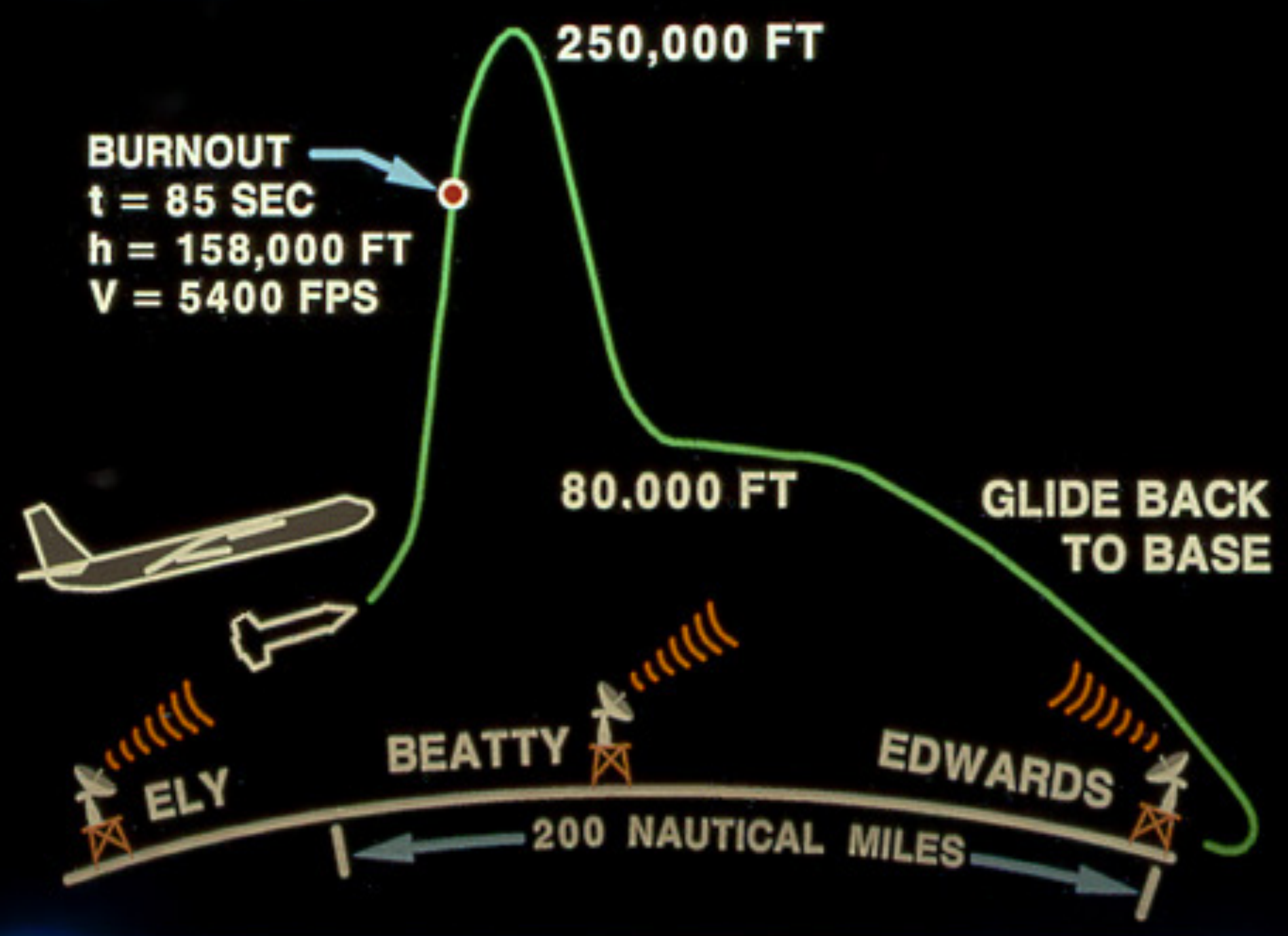

Slide Courtesy of X-15 Pilot Astronaut Bill Dana 


\section{The $\mathrm{X}-15-3$}

- Three different X-15 models were produced.

- All three relied on a Stability Augmentation System - the first 2 models had pilot-selectable control gains.

- The MH-96 Adaptive Flight Control System was unique to the X-15-3 - provided automated gain control and automated engagement of reaction controls.

- Pilot's display in X-15-3 was importantly different from first 2 models. 


\section{The Attitude Director Indicator in the X-15-3}

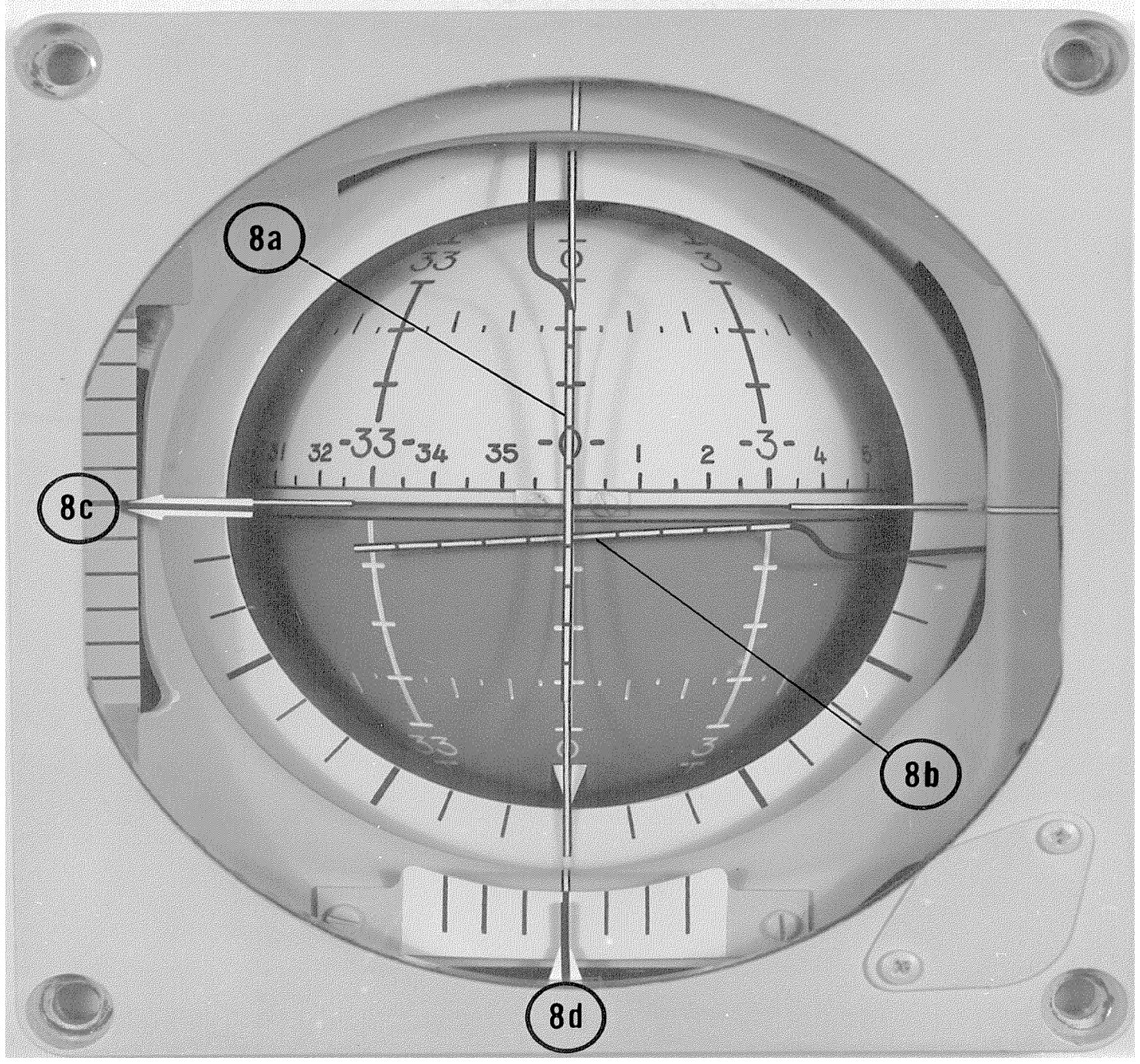




\section{Pilot's Display Panel in the X-15-3}

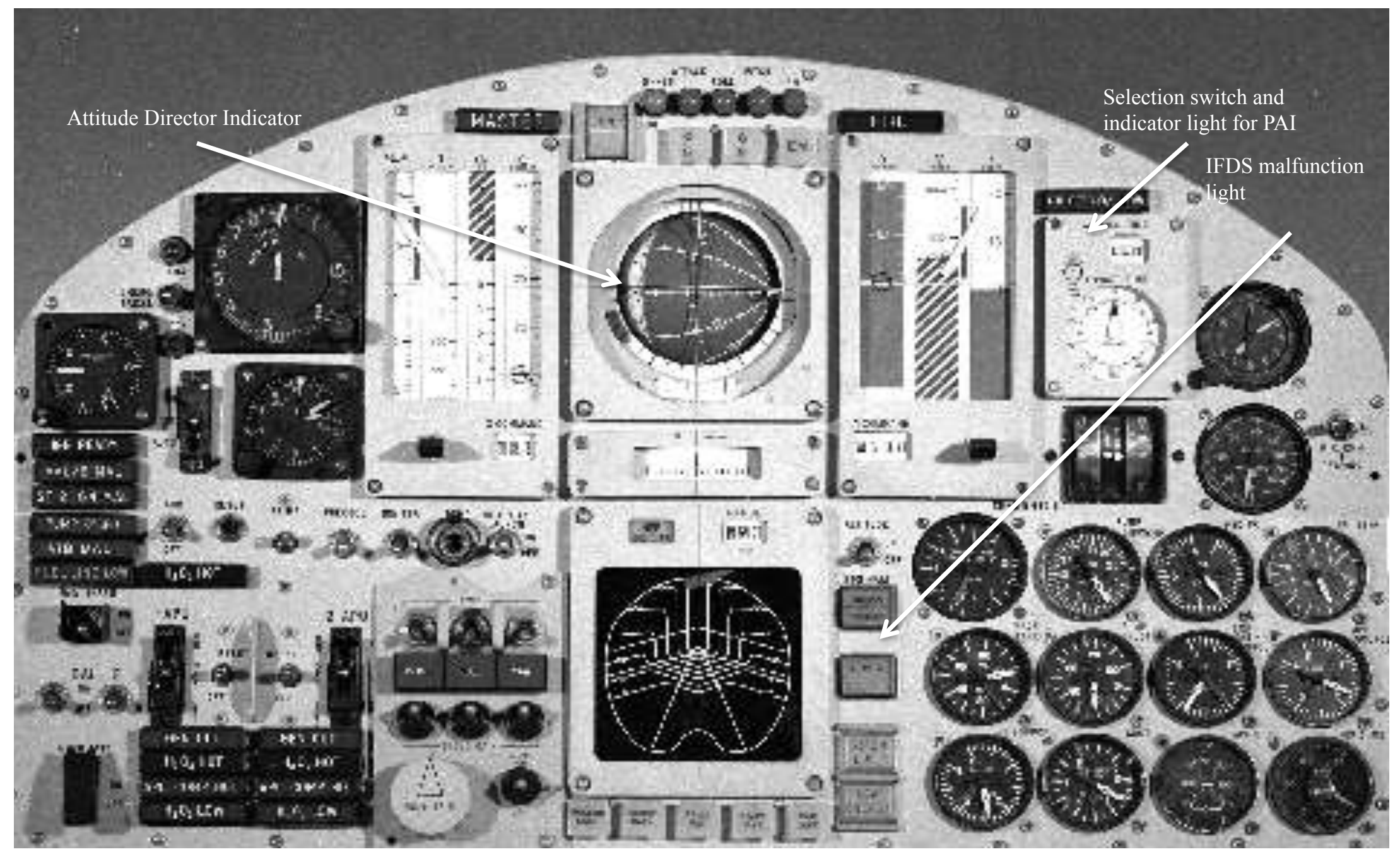




\section{The MH-96 Adaptive Flight Control System}

On X-15-3, the MH-96 AFCS was intended to provide:

* Automatic control of the gain of inputs to the aerodynamic control surfaces in all three axes as a function of dynamic pressure

* Automatic engage/disengage of the reaction controls

* Ability to use the right side stick for both aerodynamic and reaction controls 


\section{Configuration of X-15-3 and Plan for Flight 3-65}

- $65^{\text {th }}$ flight of the $X-15-3$.

- A high altitude flight -max altitude 250,000 feet.

- Flight plan and configuration similar to previous two X-15-3 flights.

- Flight 3-65 had a full schedule of maneuvers and experiments including:

bow-shock standoff measurement, solar-spectrum measurements, ultraviolet exhaust-plume measurements, and micrometeorite collection.

- Differences in configuration of the X-15-3 for Flight 3-65 included a traversing probe installed in the pod of its right wingtip that was operated for the first time in a high-altitude flight. 
The Wing-tip Pod for Experiment Installation

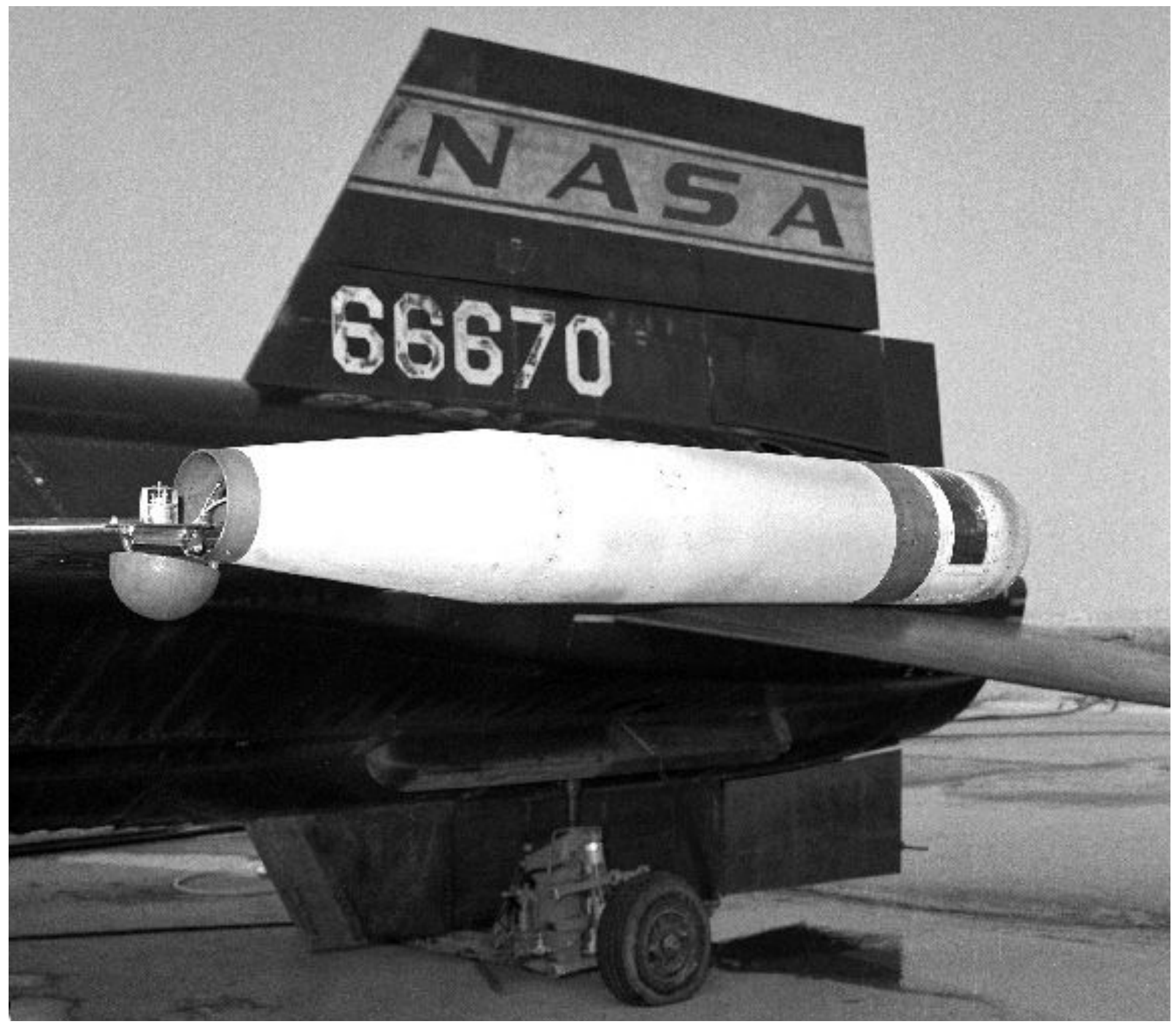




\section{Typical X-15 Altitude Mission}

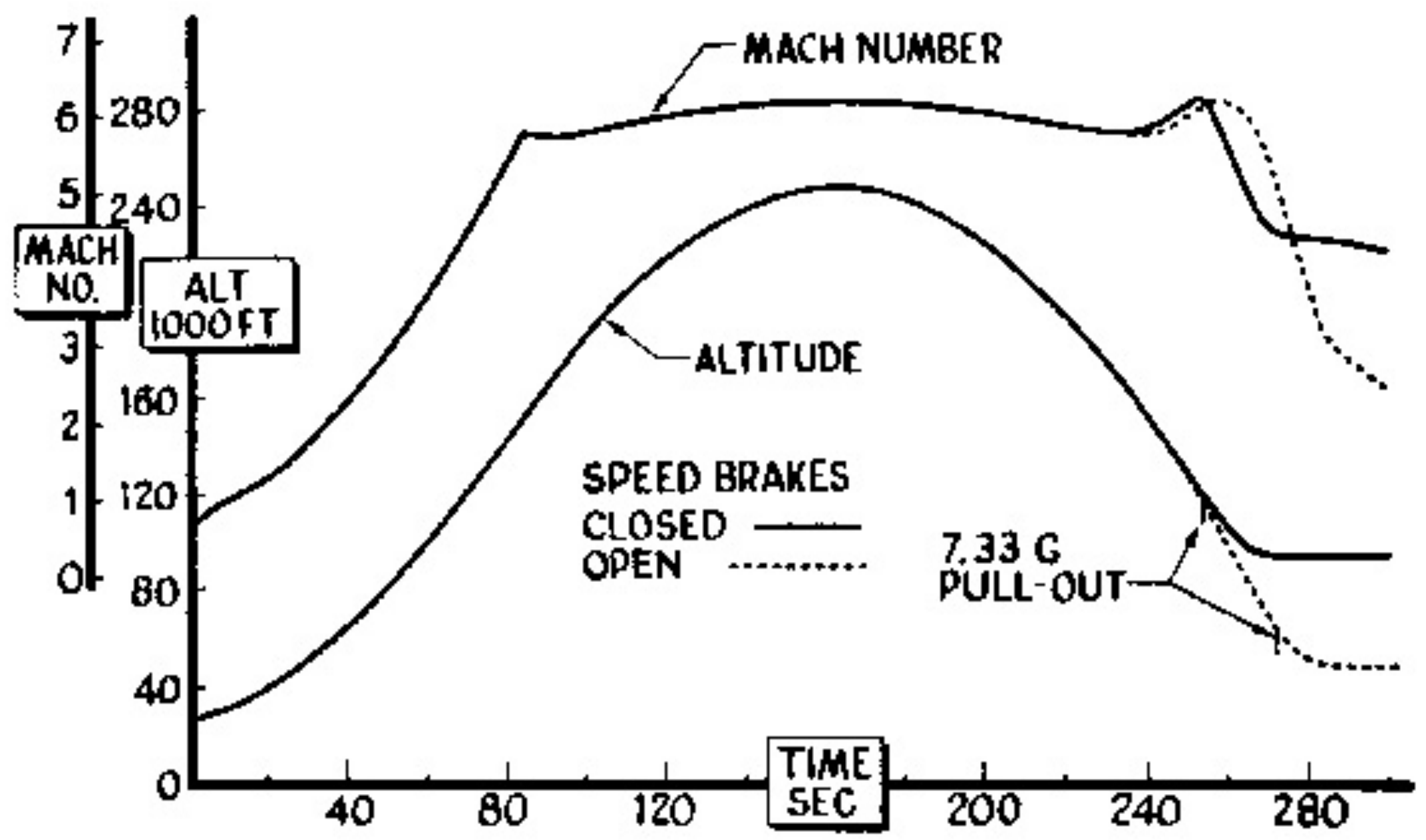




\section{Key Events During Flight 3-65}

10:30:07 - Launched from B-52 at 45,000 ft. altitude with all systems operating normally, the pilot ignited the boost rocket, and the X-15-3 accelerated into a steep climb.

10:31:07 - at about 90,000', arcing from the motor drive of the traversing probe caused an electrical disturbance to the aircraft's electrical system that continued until 10:33:53. Noise begins in all telemetered data channels.

10:31:28 - Major Adams reported IFDS computer- and the instrumentmalfunction lights. Ground Control acknowledged report. (\& 10:31:58)

10:31:34 - Pilot switched ADI to PAI mode and switched source of data for $\alpha$ and $\beta$ as well as for altitude and velocity from the nose ball to IFDS and IMU (while the malfunction lights were still on).

10:31:40 to 10:32:00 - Executed wing-rock maneuver; exceeded specified bank angles started a slow yaw drift to the right.

10:32:08 to 10:32:23 - Executed the computed $\alpha / \beta$-check maneuver.

10:32:50 - Initiated the Precision Attitude-Tracking Task 


\section{Key Events During Flight 3-65 (continued)}

10:32:51 - The Flight Controller reported to pilot, "Over the top at about 261".

10:33:01 - The Flight Controller told the pilot that he was looking "real good".

10:33:05 - The pilot switched to direct control of the RCS using the left side stick. Major Adams continued to try to complete execution of the precision attitude-tracking task.

10:33:25 - The Flight Controller once again assured the pilot that he was " $a$ little bit high," but in "real good shape."

10:33:39 - The pilot reported that the aircraft control seemed "squirrelly." 10:34:01 - Major Adams said, "I'm in a spin." (\& 10:34:16; 10:34:19)

10:34:30 - After three revolutions, the aircraft came out of the spin and went into a 45-degree inverted dive.

10:34:37 - the MH-96 AFCS entered into a limit-cycle instability forcing control surfaces into rapid, cyclic oscillation to their limit of travel at their maximum rate of $26^{\circ}$ per second. 
10:34:54 - The aircraft began to break up.

10:34:58 - The largest pieces impacted the ground 


\section{Time Line of Critical Events Prior to Spin}

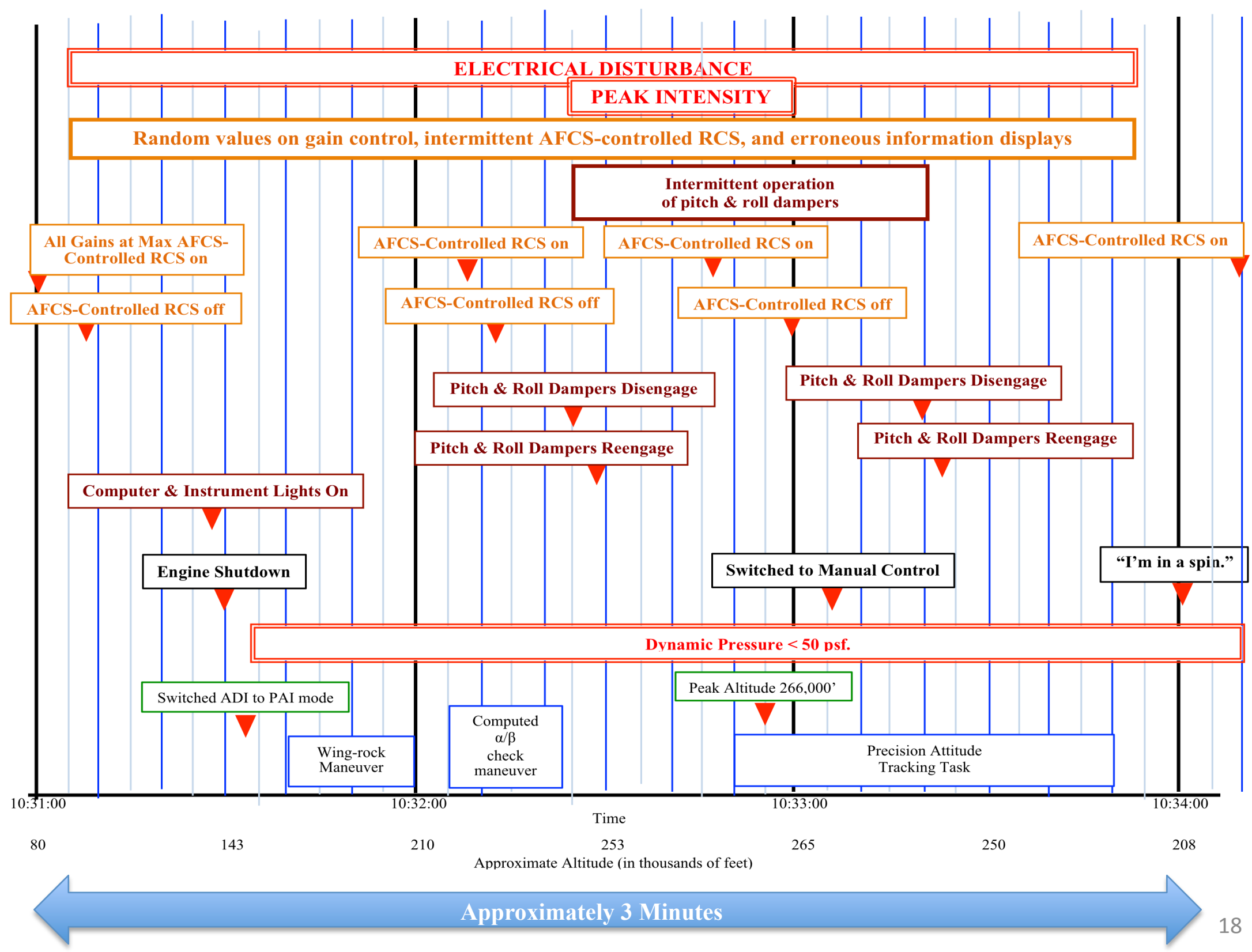




\section{Time History of MH-96 Gains During Flight 3-65}

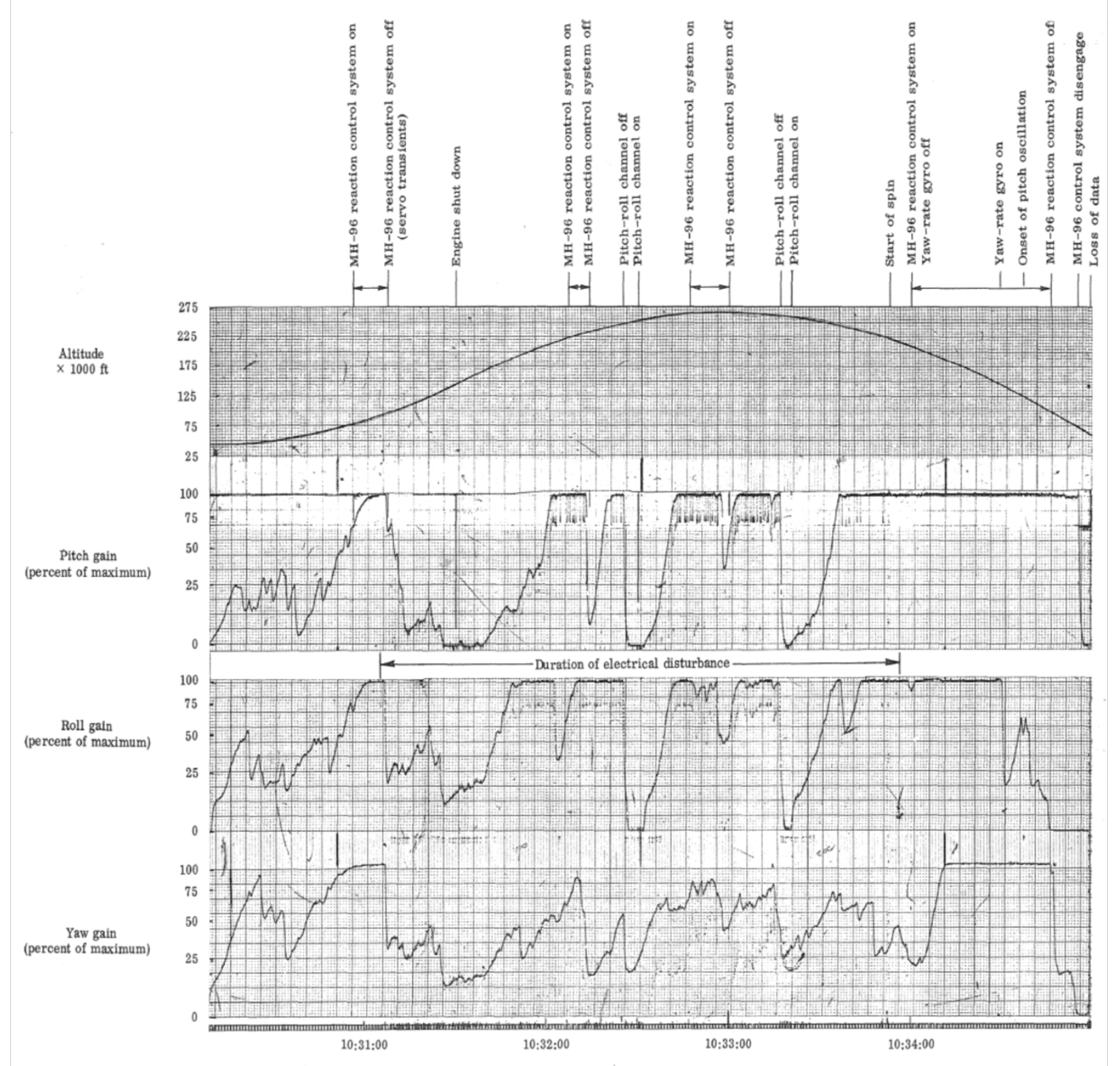




\section{Time history Telemetered Parameters of Flight 3-65}

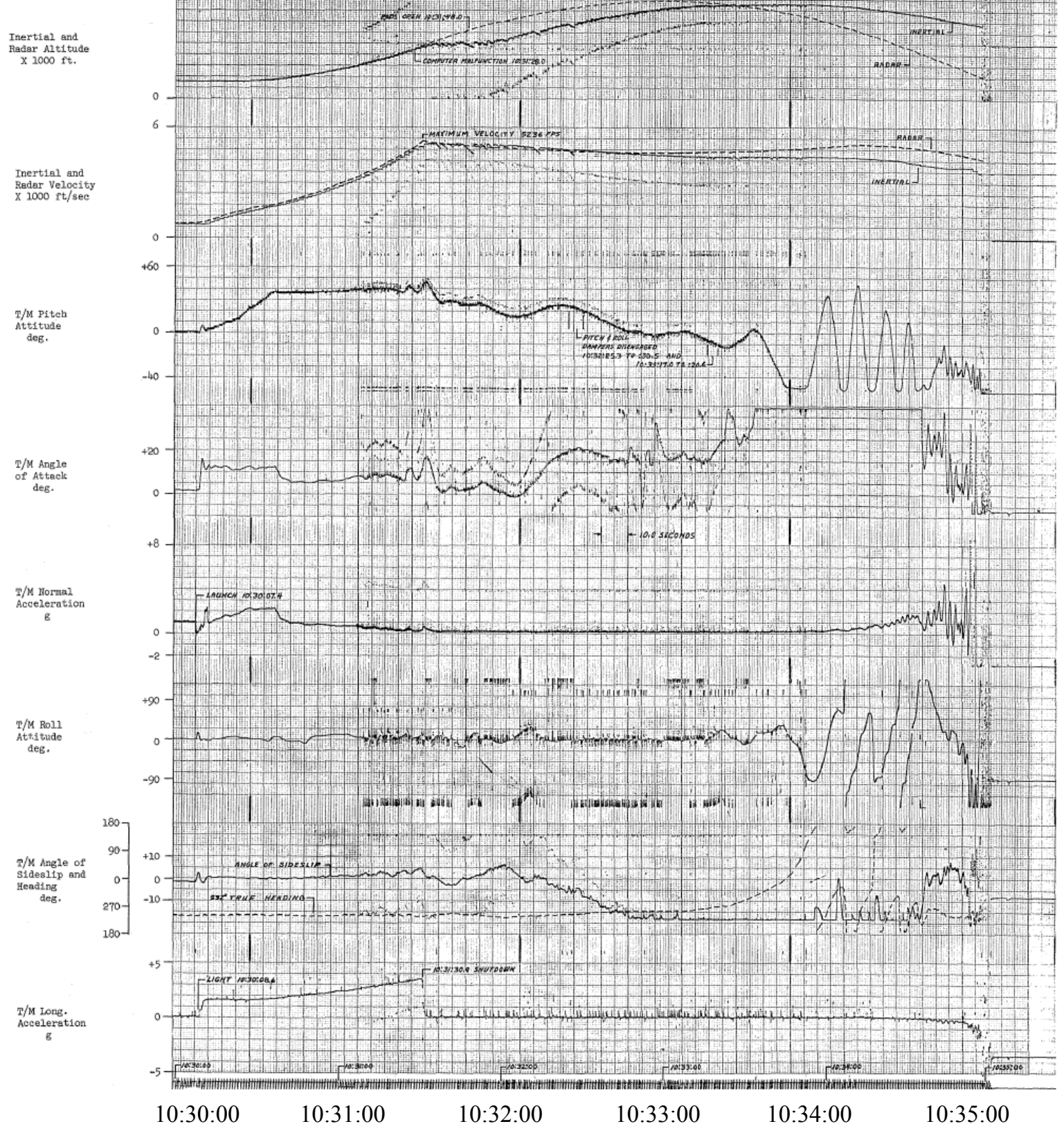




\section{Causal Factors of the X-15-3 Accident}

A Latent Causal Factor of the Flight 3-65 accident was management's failure to require environmental testing of experimental equipment before it was installed on the aircraft (equipment not considered "flight critical").

A Proximate Causal Factor was the confluence of the failures of

1. the aircraft system design and

2. ground control

to alert the pilot to the possibility of control problems and erroneous data when indications of malfunctions were observed. 


\section{Ground's evidence of problems}

$>$ At 10:31:07 (just 1 minute after launch), all of the telemetered data suddenly became erratic and remained so for several minutes.

> Starting at 10:31:07, the telemetered data on altitude and velocity differed from the radar data and was noted by a ground controller.

$>$ At 10:31:58, the Flight Controller acknowledged the pilot's report that the IFDS computer and instrument malfunction lights were on.

$>$ Between 10:31:40 and 10:32:00, during the wing-rock maneuver, a member of ground control reported to the Flight Controller that the pilot was having a control problem based on his observations of larger than normal pitch-roll servo excursions.

$>$ At 10:32:26, disengagement of the pitch and roll dampers was reported by the pilot and acknowledged by the Flight Controller. 


\section{Key Flight Control Transmissions During Flight 3-65}

\section{0:31:07 - Evidence of problems}

10:31:13 - "Okay, right on track."

10:31:21 - "On profile, on heading."

10:31:45 - "Rock your wings and extend your experiment, Mike."

10:31:50 - "On heading, on profile."

10:31:58 - Pilot reports "I've got a computer and instrument light!"

10:32:14 - "Check your computed $\alpha$ now."

10:32:19 - "Right on the track."

10:32:28 - Pilot reports "I lost my Pitch \& Roll Dampers!"

10:32:43 - "You are looking real good, right on the heading, Mike."

10:33:01 - "Your heading is going in the right direction, Mike, real good." 10:33:25 - "A little bit high, Mike, but real good shape."

10:34:01 - Pilot reports "I am in a spin!"

10:34:03 - "Let's get your experiment in and the camera on." 


\section{Contributing Factors to the X-15-3 Accident}

1. The MH-96 AFCS had a known tendency to go into limit-cycle oscillations when the system was operating at or close to maximum gain.

2. The design of the adaptive gain control in the MH-96 allowed a failure in the AFCS to interfere with the pilot's ability to control the aircraft.

3. The pilot's display used a single critical instrument, the Attitude Director Indicator, in two different modes; one a normal mode used most of the time, the other a mode (Precision Attitude Indicator) that was used only occasionally.

4. There was no provision for backup source of reliable information for the pilot at high altitude when the IFDS computer malfunctioned.

5. A speculation in the AIB report and elsewhere was that Major Adams' susceptibility to Type II Spatial Disorientation was a Contributing Factor in the scenario of this accident. 


\section{Contributing Factors to the X-15-3 Accident (cont.)}

6. Major Adams did not correct the error in yaw when he switched to direct control of the RCS through the left side stick.

7. Evidence suggests that Major Adams' responses to the PAI were consistent with an ADI mode when he switched to the left-hand stick control of the RCS.

8. Evidence indicates that Major Adams forgot to disengage the MH-96 AFCS as he was supposed to when he switched to the left side stick control. 
1. The electrical disturbance due to arcing of unqualified experimental equipment precipitated the accident.

2. The pilot had no reliable control during the electrical disturbance.

3. The pilot was, very likely, unable to recognize the control problems.

4. Flight 3-65 would have very likely been recoverable, if ground control had aborted the mission when they had clear indications of malfunctions.

5. The focus of Major Adam's attention on performing the precise wing-rock maneuver using an intermittent RCS may have distracted him from noticing the yaw angle acquired during the boost phase. 


\section{Conclusions (cont.)}

6. There was no evidence that Spatial Disorientation degraded Major Adam's performance during the boost phase or the execution of the experimental maneuvers.

7. The pilot's ability to manage the aircraft's various malfunctions when he switched to direct control was affected by an extremely high workload.

8. The limit-cycle oscillations of controls would have probably been prevented had Major Adams disengaged the MH-96 AFCS when he switched to manual control.

9. The destruction of the X-15-3 was due to the structural loads produced by the high frequency limit-cycle oscillations of the control surfaces induced by the AFCS. 


\section{Thank you!}
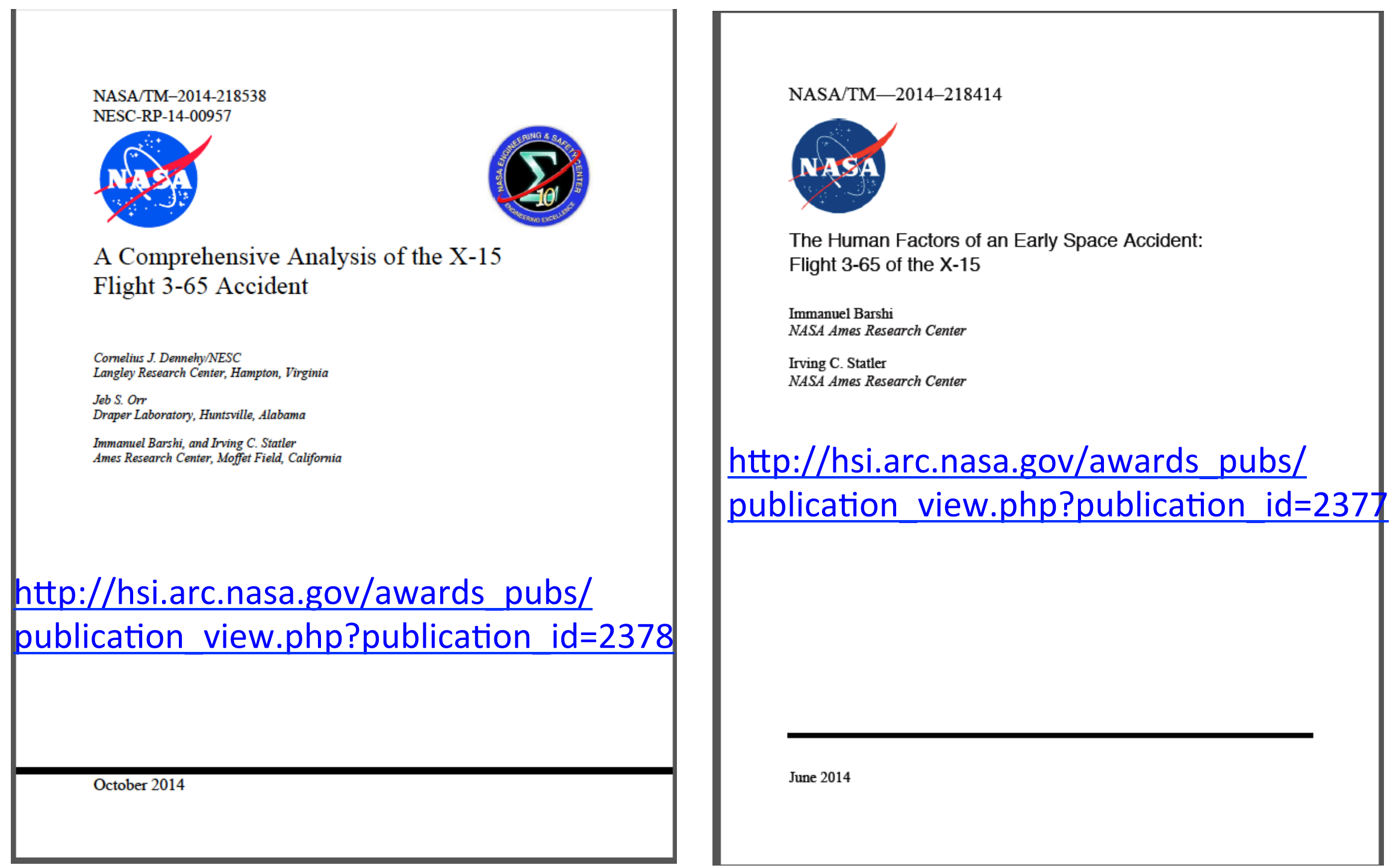

For questions, contact me at: Immanuel.Barshi@nasa.gov 